Please do not remove this page

RMIT

UNIVERSITY

\title{
Designing digital and creative scaffolds to strengthen Indigenous nations: being Wiradjuri by practicing sovereignty
}

Akama, Yoko; Evans, Debra; Keen, Seth; McMillan, Faye; McMillan, Mark; West, Peter

https://researchrepository.rmit.edu.au/esploro/outputs/9921861656601341/filesAndLinks?institution=61RMIT_INST\&index=null

Akama, Y., Evans, D., Keen, S., McMillan, F., McMillan, M., \& West, P. (2017). Designing digital and creative scaffolds to strengthen Indigenous nations: being Wiradjuri by practicing sovereignty. Digital Creativity, 28(1), 58-72. https://doi.org/10.1080/14626268.2017.1291525

Document Version: Accepted Manuscript

Published Version: https://doi.org/10.1080/14626268.2017.1291525

Repository homepage: https://researchrepository.rmit.edu.au

(C) 2017 Informa UK Limited, trading as Taylor and Francis Group

Downloaded On 2023/04/26 22:05:18 +1000 
Thank you for downloading this document from the RMIT Research Repository.

The RMIT Research Repository is an open access database showcasing the research outputs of RMIT University researchers.

RMIT Research Repository: http://researchbank.rmit.edu.au/

\section{Citation:}

Akama, Y, Evans, D, Keen, S, McMillan, F, McMillan, M and West, P 2017, 'Designing digital and creative scaffolds to strengthen Indigenous nations: being Wiradjuri by practicing sovereignty', Digital Creativity, vol. 28, no. 1, pp. 58-72.

See this record in the RMIT Research Repository at:

https://researchbank.rmit.edu.au/view/rmit:42961

Version: Accepted Manuscript

Copyright Statement:

(C) 2017 Informa UK Limited, trading as Taylor and Francis Group

\section{Link to Published Version:}

https://researchbank.rmit.edu.au/view/rmit:42961 


\title{
Designing digital and creative scaffolds to strengthen Indigenous nations: being Wiradjuri by practising sovereignty
}

Yoko Akama, Debra Evans, Seth Keen, Faye McMillan, Mark McMillan \& Peter West

\begin{abstract}
The proliferation of digitally mediated DIY practices constitutes new modalities of political expression and participation, shaping how citizenship is enacted and performed. However, our paper begins by problematizing concepts of citizenship in media and communication contexts that only speaks to identity-formation. For Indigenous Australians, citizenship does not need to be asserted or constructed-they are sovereign and they have never ceded their land, rights or identity. Pursuing this argument, we share insights of various digital and creative scaffolds that are being designed with Wiradjuri people as continuous 'infrastructuring' to express and practice Wiradjuri sovereignty. This exploration is enabling a political identity to form and creating multiple places to be Wiradjuri together. We also discuss how designing digital and creative scaffolds can be considered as a meeting place of sovereigns, to attend to a consciousness that non-Indigenous people are also practising their own sovereignty in relation to respecting Indigenous sovereignty/ies.
\end{abstract}

\section{KEYWORDS}

Participatory design; Indigenous Nation; sovereignty; Australia

\section{Introduction: Indigenous sovereignty and citizenship}

This paper speaks to digital creativity-specifically on social media, design and creative citizenship-by questioning the popular framing of digital and creative practices as emerging forms of citizenship. For us, this raises concerns of overemphasizing selfdetermination as a disaggregate, atomized self that is 'free' to construct an identity and individuality through the digital, media and material choices onoffer. This repurposed notion of citizenship is problematic in the context of Indigenous Australia where their rightsbased approach is enacted not as individuals who gain or express their citizenship through participating in critical making or digital cultures. We argue from the premise that citizenship does not need to be asserted or constructed through such practices, because for Indigenous nations in Australia, this has always existed. Aboriginal and Torres Strait Islander peoples are sovereign and they have never ceded their land, rights or identity. This is a necessary foundation for Indigenous recognition and self-determination, to build mutual respect between Indigenous and non-Indigenous Australians, and avoid being caught or claimed within a colonial construct (Behrendt 2003). This approach reinstates Aboriginal and Torres Strait Islander communities as Nations with distinct language, culture, knowledge and governing systems long before colonization. Recognition of Indigenous sovereignty is a political argument for the achievement of rights and autonomy to demand transference of power from the Australian state (Behrendt 2003).

The term 'sovereignty' is used here deliberately, despite being met with suspicion and opposition by non-Indigenous people who see the claim as 'radical, subversive and dangerous' because of its common uses in international law (Behrendt 2003, 95). Building on Larissa Behrendt's pioneering work in law and Indigenous social justice, we use 
sovereignty as a footing and recognition of Indigenous people, reinforcing her argument that '[ $r$ ]ather than being the aim of political advocacy, it is a starting point for recognition or rights and inclusion in democratic processes' (Behrendt 2003, 95, original emphasis). Wiradjuri man and Indigenous lawyer, Mark McMillan, further emphasizes the importance of sovereignty as a necessary starting point to creating a political environment and transform relationships between the broader Australian society and increased autonomy for Indigenous people (Behrendt 2003). As such, sovereignty is used in our paper to frame citizenship of Indigenous Australians to their individual Indigenous nations, and forge lawful relations between Indigenous and non-Indigenous Australians.

Mutual recognition of sovereignty between and among Indigenous nations as well as by non-Indigenous people in Australia is drawn into sharp focus in this paper. This lawful relationship exists through respecting the sovereignty of Indigenous peoples, on whose land non-Indigenous people are located, situated and practice their own sovereignty as being in relation to Indigenous sovereignty/ies. Such understandings of citizenship and sovereignty are central to our paper's discussion. Assertions of, and to, sovereignty can be seen as an analytical tool for non-Indigenous peoples and 'their' sovereignty. This is an interrogation of their own ways of knowing that term, its meaning and its possible contribution for sovereign relationships with Indigenous peoples and nations. In this way, the paper calls on nonIndigenous peoples to critically engage with their sovereignties and question their obligations to the sovereign relationships that have existed since the moment of colonial contact.

In this framing, we draw upon several initiatives that involve digital design and media practices that are assisting expressions of Wiradjuri sovereignty. We discuss how these practices constitute Indigenous Nation Building (INB) in Australia in the absence of formal nation recognition by Australian governments (Vivian 2014). The initiatives we discuss are political, to disrupt hegemony and forcibly challenge Australia's colonial history of Indigenous cultural extinction coupled with past government policies of assimilations and current policies that focus on Indigenous disadvantage.

The authors are an interdisciplinary mix of Wiradjuri, Indigenous and non-Indigenous scholars in law, design, health, media and Indigenous education. Our initiative is a component of a larger and ongoing research on emergent theory and practice of INB. This has been funded by several research grants and multiinstitutional partnerships to promote governance and capacity building for Indigenous nations to exercise jurisdictional power and self-determine economic development in accordance with Indigenous nation's identified goals (Gooda 2014; Hemming, Rigney, and Berg 2010). INB in Australia has been founded on the work undertaken by the Harvard Project on American Indian Economic Development and the Native Nations Institute at the University of Arizona. ${ }^{1}$ In particular, Cornell's (2015) scholarship on ways for Indigenous nations to 'Identify, Organize and Act as Nation' informs an emerging Wiradjuri consciousness.

We are collaborating with members of the Wiradjuri Nation, which has one of the largest territories on the Australian eastern seaboard. Their Country is bordered by the Macquarie, Lachlan and Murrumbidgee rivers which provided trails for western expansion of the colony of New South Wales in search for grazing country, resulting in the Nation being subjected to 
some of the most profound impacts of colonization from early days of the colony (Read 1988). The Wiradjuri have experienced extensive dispersal of its citizens through forced relocation and the establishment of numerous missions. Resettlement urban centres on Wiradjuri Country are generally heterogeneous with a number of regional towns containing Wiradjuri, non-Wiradjuri Aboriginal and non-Indigenous populations. This heterogeneity features in our paper in various ways that speaks to existence between settler and Wiradjuri laws; how multiple Indigenous nationalities of a person become foregrounded when nationspecific relations and cultural engagements take place; and informing poly-vocal notions of 'braided voices' through the digital and creative materials we designed.

In spite of this geographic dispersal, many Wiradjuri individuals and groups possess a strong cultural identity and are actively exercising responsibility for their Country. Our research team is exploring various mechanisms for this mobilization and share some salient examples. Some Wiradjuri have begun to ask what an identifiable political community might look like that aspires to self-govern its own future. Such communities include within, and through digital space/s. A concrete sense of a single nation to build governing institutions is still emerging, including ways to cohere Wiradjuri people to promote collective identity, and translating cultural identity to political identity over the long term. Furthermore, its considerable size is a significant challenge, compounded by a large Wiradjuri diaspora who live off their traditional homeland ('off Country') in major cities like Sydney and Melbourne. Place and place-making as dynamically and socially constructed notions are elaborated further in the paper to describe how digital and creative scaffolds are catalyzing practices of being and acting sovereign, which is of particular importance to Wiradjuri living 'off Country'. We see that this is sovereign existence without knowing or being on Country. Several Wiradjuri-led events 'on' and 'off Country' have been undertaken to catalyze, scaffold and promote necessary discussions of self-governance, sovereignty, cultural renewal and political identity. These events shift existing gatherings, such as the Hands On Weavers group that revive traditional weaving practices in the Riverina region of Australia, towards a nation-building activity, such as Dabaamalang Waybarra Miya ('mob of people weaving together, acting in concert'). Aunty Lorraine Tye, a Wiradjuri Elder and master weaver of the Hands on Weavers group, and Linda Elliott, an artist and curator of Wagga Wagga Art Gallery, spearheaded Dabaamalang Waybarra Miya event 'as an opportunity to bring other like minded artists to exchange skills, reclaim knowledge surrounding gathering of materials and to develop ways of utilizing weaving practice as vehicle for nation building' (see http://sovereignweaving.com/). This example illustrates that while renewing cultural practice, the consciousness of nation building makes weaving a sovereign act.

For the three authors in design, media and communication whose disciplines create, critique and imagine material cultures and sociodigital spaces, their motivation is to explore the invisible, fluid and vernacular diversity in which Indigenous sovereignty is being practised through such spaces. Aboriginal media in Canada like 'screen sovereignty' (Dowell 2013), Aboriginally determined online space CyberPowWow (www.cyberpowerwow.net) and Indigenous Media in South America (Graham 2016) inform and inspire their work. The digital and creative materials we speak of range in scale and variety, from publicly accessible social and printed media, websites, radio broadcasts and a Wiradjuri digital platform that is specific to and accessible only by Wiradjuri participants. Bespoke digital and print collaterals have been designed by non-Indigenous communication designers, whereas other forms like 
radio broadcasts, facebook and twitter that mobilized various Wiradjuri led events utilize established structures for interaction and communication (see the bricolage as Figure 1). All the events were Wiradjuri-led, organized by key Wiradjuri Elders, leaders and advisory groups, and most bespoke materials and the digital platform evolved through co-designing workshops and prototyping sessions that were undertaken with our Wiradjuri partners. This partnership leverages professional and institutional resources, expertise and experiences that the design and media team have access to, towards pursuing mutual objectives, making this a typical configuration among many Indigenous-led media projects. Graham (2016), an anthropologist of South American Indigenous media, points out that such projects are mutivocal and always contested. This means that while we echo Dowell's $(2013,4)$ notion of 'screen sovereignty' for Aboriginal filmmakers to 'reclaim the screen to tell their own stories by taking the means of media production into their own hands', the paper attempts to further nuance the heterogeneous configurations, including invisible, systemic, and nonhuman assemblages that can participate in the process of practising and expressing Wiradjuri sovereignty.

This means, rather than describing isolated and independent objects and detailing the design methods used in each, we cohere them under what we call digital and creative scaffolds. They are assemblages that are always undergoing socio-material alignment in fluid, emergent and contingent ways (Björgvinsson, Ehn, and Hillgren 2010). This framing will be elaborated further in the paper through theory and methodologies in participatory action research and participatory design, and in particular, scholars who are exploring dynamic, relational configurations like 'infrastructuring' (DiSalvo, Clement, and Pipek 2013; Star and Ruhleder 1996). We discuss how designing these digital and creative scaffolds can be considered as 'infrastructuring' the practice of Wiradjuri sovereignty and catalyzing lawful relations, which are continuously built and come into being relationally through the socio-material encounter. 


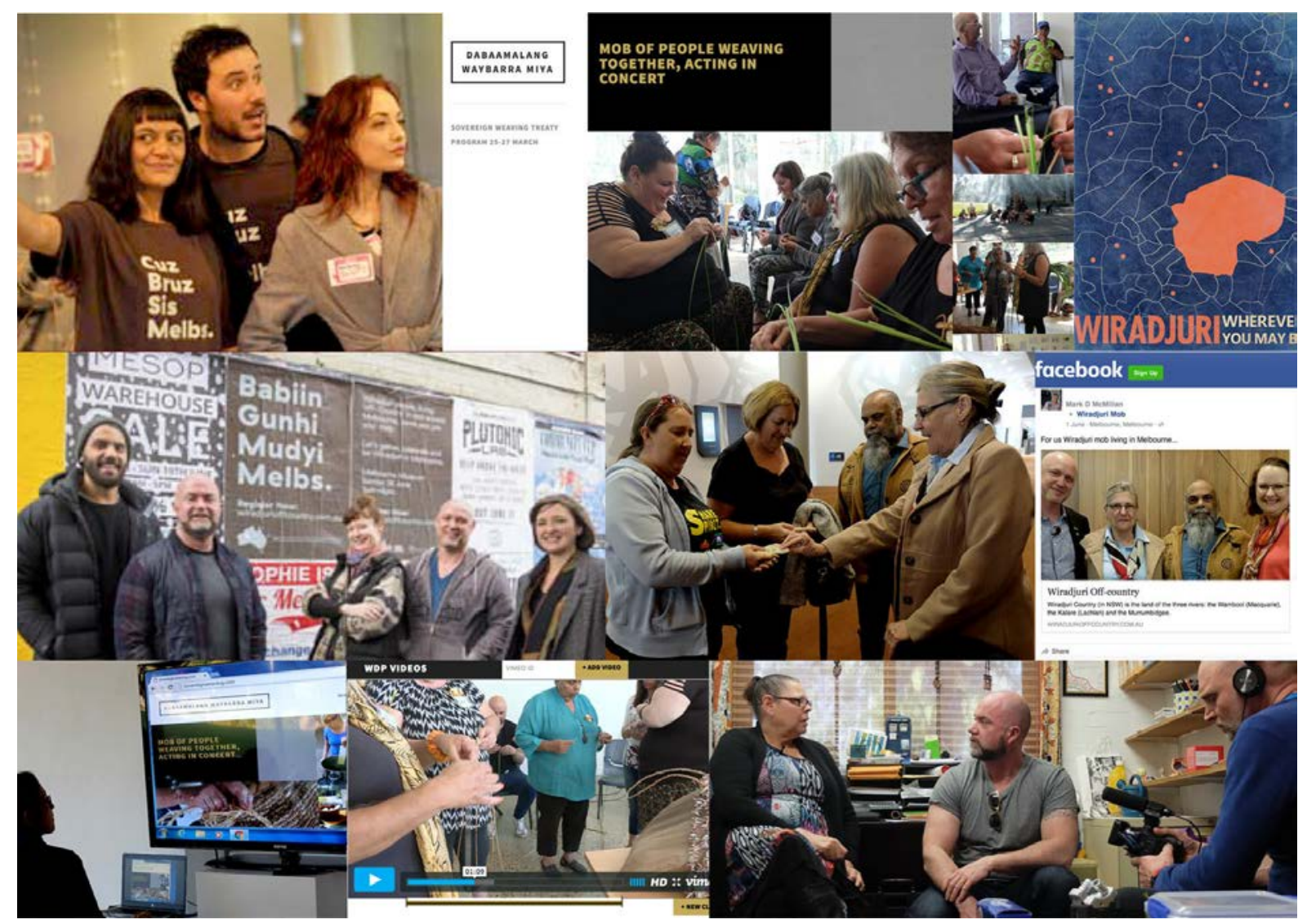

Figure 1. A bricolage of various digital and creative scaffolds.

Our paper also speaks to the lawful relations among the co-authoring team as a reflexive way that inscribes how our own ontologies as citizens are ongoingly made through our collaboration. These are important to disclose precisely because these dimensions at work often remain implicit, due to disciplinary privileges in design and Human Computer Interaction $(\mathrm{HCl})$ that prefers methods, techniques, materials and outcomes as knowledge. Resisting this disciplinary orthodoxy is the work of this paper. As such, we pursue ways to immerse and entangle, rather than separate, simplify or generalize the relational dimensions that underlie multiple enactments of sovereignty. Lawful relationships mutually respect the centrality and interplay of culture-of Wiradjuri and of those individuals comprising the team - and this being the foundation upon which to create works that have cultural legitimacy and match for Wiradjuri. 'Cultural legitimacy and match' are specifically INB principles, which Cornell (2015) observes are articulated differently in Australia, because they are deployed by different Indigenous Australian nations and their understanding. These relationships borne through trust and honesty throughout the design process allow for a greater depth of yarning, because the team do not exist 'outside' such moments, but are intimately woven into the conversations of practising their own sovereignties.

\section{Citizenship through creative and digital scaffolds}

We are witnessing an explosion in digitally mediated DIY practices that constitute new modalities of political expression and participation, shaping how citizenship is enacted and performed. This paper also adds an extra dimension by bringing into relation different sovereignties and citizenships that coexist and reside in Australia's sovereign polities. Even 
benign ways in which people are sharing craft patterns and repair tutorials online are a political act, perhaps not overtly to challenge authority, but to actively seek, carve out and inhabit spaces in which to operate outside of standardized and commercialized systems of production and consumption. These are noted as 'critical makers' or 'DIY citizens' by the cultural theorist, Hartley (2009) who describes horizontal processes of leadership and decision-making by those who believe in their rights to self-determine their own identity and individuality. Self-determination here is 'semiotic' through media consumption (Chidgey 2014). This disaggregation can overemphasize an atomized self that is 'freely' constructed through the digital, media and material choices on offer to be who ' $I$ ' want to be at times that suit 'me'. The editor of Critical Making, Social Media and DIY Citizenship, Ratto and Boler $(2014,5)$, play with the tension evoked by 'DIY citizenship' to explore 'how and when individuals and communities participate in shaping, changing, and reconstructing selves, worlds, and environments in creative ways that challenge the status quo and normative understandings of "how things must be"'. However, such notions of 'creative citizenship' that is context-specific to communication and media studies are confined to notions of identity-formation, and less about attending to pre-existing structures such as rights, obligation, power and relations with the state. This makes it problematic for our paper's agenda when Indigenous people cannot be considered as individuals who 'gain' or 'express' their citizenship through participating in 'critical making' digital cultures. While formation of a political identity is a significant dimension to Wiradjuri nation building, echoing the creative DIY or DIT (do-ittogether) activism and self-organization, it is important to remember that citizenship in our paper attends to the rights for Indigenous people and respect their cultural laws.

Examples of DIY/DIT citizenship have a tendency to assume a certain kind of participation where egalitarianism and democracy for involving anyone are valued. Yet, participation has different meanings in different cultures. We build on concerns raised by many researchers in participatory design like Nic Bidwell (Bidwell and Hardy 2009; Bidwell et al. 2008), Margot Brereton (Brereton et al. 2014) and Heike Winschiers-Theophilus (Winschiers-Theophilus et al. 2010) who are known for working closely and in partnership with Indigenous peoples in Australia and South Africa. These scholars report critical issues regarding culturally sensitive methods of engagement, the process of knowledge generation with Indigenous people and considerations for how the community benefits from the research. Other identified challenges include bridging knowledge systems, especially when translating local Indigenous knowledge into appropriate information and communication technologies (ICTs). Winschiers-Theophilus and colleagues (2012) observe how values that shape and guide participation can often remain tacit or are not obvious by outsiders of a community of practice. Age, gender and social status can determine ways in which opinions are shared and made public. These complex and contested notions of participation impact on the design of digitally mediated spaces and how people participate there.

As such, we are careful not to speak of participation as a literal and physical way Wiradjuri people provide input and create content through digital materials, without discounting the importance of such involvement. Being led by an Indigenous worldview means to acknowledge many dimensions that configure relationally in being and becoming, including non-human and invisible elements (Tuhiwai-Smith 2012). This view informs our way of seeing participation of people, culture, knowledge, practices, language, feelings, 
experiences, place, environment, weather, spirits, animals, ancestors and atmospheres and more that are all transforming as well as being part of the world's continual transformation (Akama 2015; Ingold 1993).

Building on this heterogeneous view, acts of designing, making, creating can be both material and immaterial-poster, website, digital platform, meeting, atmosphere, event, conversation on radio or social media. Our team, Wiradjuri partners and beyond participated in such making, and we refer to these as mechanisms for on-going 'infrastructuring' practices of Wiradjuri sovereignty. The specifics of how and what was created are elaborated in the sections that follow. Infrastructuring extends Star and Ruhleder's (1996) pioneering ethnographic work that observed embedded knowledge, practices and socio-material structures in organizations that are continuously built and comes into being relationally. Highlighting the verb ('-ing') shifts 'infrastructure' that connotes a rigid, physical substrate like roads or power lines, to that which is always undergoing socio-material alignment (Björgvinsson, Ehn, and Hillgren 2010; DiSalvo, Clement, and Pipek 2013). We resist constructs that separates and categorizes, instead, see sovereignty constituted through fluid, emergent and contingent assemblages. These combine to form scaffolds-like a building site that uses temporary, movable structures that combine together to construct new things-that are also continually remade as a movement of INB. Here, we also echo the notion of 'scaffolding' in education and cognitive psychology (Vygotsky 1978; Wood, Bruner, and Ross 1976), where learning is supported by the construction of temporary structures to provide alternative routes to cooperative learning and problem-solving. As such, 'creativity' and 'designing' are less about demarcating special qualities to material, characteristic, process or expertise; rather, following Sanders (2002), our work harnesses the collective creativity of people, expressed in everyday acts to explore ways to scaffold these as one component of INB.

\section{Digital and creative scaffolds: documenting 'on country' conversations}

Through invitation, the design and media team have been documenting various activities, events and conversations since 2015 that are enacting Wiradjuri sovereignty on Country. Many people, including Elders, Indigenous and non-Indigenous participants involved in tertiary education, Wiradjuri language courses and arts practice were invited by prominent Wiradjuri leaders to gatherings at Wagga Wagga (NSW), a major urban centre on their Country. Owing to the fortunate weather, many of these gatherings took place outdoors near the foreshore of Murrumbidgee River, a site of significance for the Wiradjuri, where we were emplaced and manifested from this particular setting, enveloped in warm sunshine, light river breeze, call of native birds and convivial atmosphere. Such place-based, ontological dimensions contour sovereignty, imbued with emotion and family history. One example is shared by Faye and Mark McMillan (Figure 2) who explain how connection to place and their history through their maternal lines of strong Wiradjuri women, particularly their grandmother Daphne Barnes, is tied to their feelings of being sovereign: 


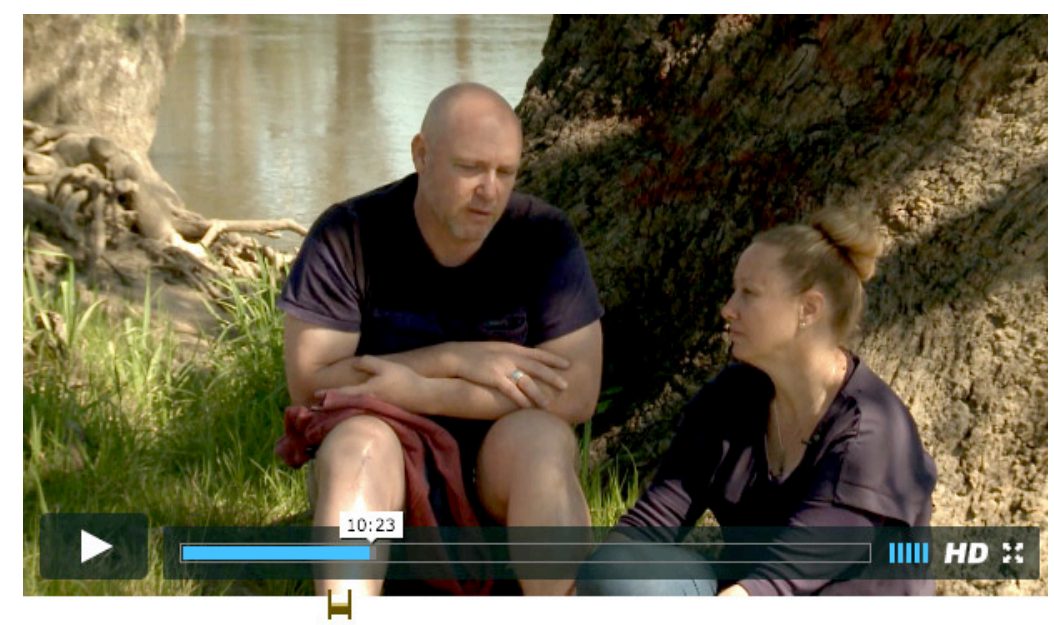

09:49-11:07

add comments here

ADD TAG

Figure 2. A screen grab from the Wiradjuri digital platform of Faye and Mark sharing their family stories by the Murrumbidgee River.

Daphne Barnes was born into the Wiradjuri world and the Settler world on 4th September 1919. She was born on Wiradjuri country at Trangie, which by 1919 was a shared placed with Settler jurisdiction of New South Wales. Nan was the daughter of Jesse Evans (Gran), a Wiradjuri woman, and a settler father (John Evans). Gran always said she was born into the Wiradjuri world on the banks of Wambool River (Macquarie River in Wiradjuri language) at Dubbo the day the first steam train came to town. That was in 1881. Gran was the Wiradjuri daughter of Elizabeth Baker, a Wiradjuri woman born on the Lachlan Valley Way in the 1860 s.

Nan passed on their Wiradjuri birthright-and ways of being and knowing Wiradjuri-to her eight Wiradjuri children with her settler husband Michael Barnes. Of the eight Wiradjuri children was our mother, Robyn McMillan (Barnes). All of Nan's children were raised in Trangie on Wiradjuri country (a small country town in the Central West of New South Wales) - with brief periods of living in Wyong New South Wales. Robyn had five children. Our siblings were raised and educated in Wiradjuri and settler law by Mum and Nan in Trangie.

Daphne Barnes was more than just our grandmother. Our grandmother was more than just an Aborigine. She was born into and with different laws. She was born into a Wiradjuri world; and she existed with the law of the settler, even though as an Aborigine the settler law tried to place her outside of itself-because settler law failed to recognize her as a Wiradjuri woman. The settler law could not know that it existed, and continues to exist, alongside Wiradjuri law. That is what Wiradjuri nation building seeks to bear witness too...that Wiradjuri sovereignty and citizenship has always existed alongside settlers and their laws. 
For Faye and Mark, Wiradjuri citizenship is a series of activities, such as sharing their family history, that maintain connection to the ways they know their Wiradjuri world. The story above indicates that connection with and between a Wiradjuri and settler past is not just indicative of how law can be known. It highlights that law-for their family-can only be seen as relational. How they know of Wiradjuri law and settler law was a practical reality, experienced day to day, moment to moment - as a way of being. One is not privileged over the other-they are Wiradjuri and settler. These exist within them as a way of being, and therefore, knowing. They share and practise this relationality. As a Western trained lawyer, Mark knows how to be with Western law, but not accept it as ontology. Mark can only know how to be in a lawful relationship to settler law through his birth right and ontological connection to place through Wiradjuri law (Moreton-Robinson 2015).

This speaks to the heterogeneity that characterizes this Indigenous space, in the multiple Indigenous and non-Indigenous heritage of a person, in the various cultures that live on Wiradjuri country, and here, in the distinct ways of knowing and attending to settler law and Wiradjuri law. Learning about sovereignty and citizenship in all its complicated forms led the design and media team to pursue the polyvocal notion of 'braided voices' (FitzSimons 2009) to document various activities, practices and place-based atmosphere on video. We then developed a Wiradjuri digital platform so that participants could review the 70+ hours of footage, select segments as 'clips', tag them with keywords, annotate with comments and categorize into themes (see Figure 2 and Akama, Keen, and West 2016 for more). In this way, the research team and participants could watch and listen to the stories to further understand what being Wiradjuri means, and also, facilitate further discussions of sovereignty. This reflects our participatory action research approach to enable collective analysis, prevent misinterpretations or things taken out of context, contrasting with normative ways in which research participants are usually asked to check interview transcripts for accuracy, but rarely invited in the process of analysis or synthesis.

We also envisaged that more Wiradjuri individuals, especially those living 'off Country' could also upload their stories and experiences to share, and in turn, tag and comment from wherever they are, thereby eliciting further conversations through ongoing contributions. Yet, such ways of creating and sharing content-common to most online platformsimmediately appeal to democratic and egalitarian values, but there is inherent incompatibility with Wiradjuri cultural protocol that determines gendered, kinship and Eldership systems of knowledge sharing, and how some individuals or groups have permission to speak for a particular people, Country and traditional knowledge, and some do not. While the footage documented so far does not pose much risk of sharing traditional knowledge, it highlights how ICTs can automatically embed Western logics and literacies that conflict with Indigenous knowledge and ontologies, as identified by other researchers in participatory design (see Winschiers-Theophilus, Bidwell, and Blake 2012).

These revelations and more fuel our collaboration with key Wiradjuri partners in the ongoing development of the Wiradjuri digital platform. Documenting acts of sovereignty and discussing these on the Wiradjuri digital platform necessitate questions of decisionmaking based on its context and content. Practical details on who videos what, where, and how such footage can be shared, and then seen by whom, are all related to matters of 
sovereignty (Dowell 2013). This complexity entangles further as we progress through the paper, so here, we suggest the importance of the Wiradjuri digital platform as a liminal space to crystallize and provoke such discussions as a continuous process of respecting sovereignty, to reveal and make material the deeper, critical questions for Wiradjuri, collective self-determination and governance. Following the notion of ontological designing (Willis 2006), this can be seen as a double-movement where artefacts, like the videos and the Wiradjuri digital platform in turn, have the potential to reconfigure, collectively produce and contingently inscribe cultural and relational practices as a living, dynamic act of being sovereign. For a geographically dispersed, heterogeneous Nation to determine an identifiable political community and self-govern its own future, we are pursuing the Wiradjuri digital platform as a methodological tool and an ontological space to catalyze discussion on culturally appropriate ways for dialogue and decision-making on Wiradjuri Nation matters.

\section{Creating a safe place for practising sovereignty 'off country'}

For many Wiradjuri, the process of identifying as Wiradjuri can be fraught with confusion and confrontation, and this feeling can multiply significantly for those living 'off country'. Individuals are subject to personal inquiry and often made to prove or explain their aboriginality, invariably through 'white' constructs, to a 'white' audience (Heiss 2012). This is frequently an impediment to identifying and therefore gathering as a cultural group. Physical attributes, cultural knowledge and geographic location all become examined as measures of an Indigenous person's compliance with the colonial construct of 'the aboriginal.' It is common for Indigenous people to feel the pressure of non-conformity to dominant 'white' notions of the authentic 'aboriginal black'. Indigenous people themselves can also be influenced by these measures. For example, community members living a perceived notion of aboriginality on Country, strong cultural knowledge and direct familial connections can, at times, combine to create a position of power which can be used as a means of intimidation or exclusion of citizenship from less culturally aware citizens (Black 2011). These measures of 'blackness' are compliances to 'white' notions of what 'blackness' should be. This is not simply the execution of cultural knowledge or expertism, but rather the prosecution of 'white' measures by Indigenous people (Purcell 2002). These measures or frameworks are at times prosecuted by Indigenous people towards other Indigenous people. Knowledge or adherence to these frameworks can denote power in the holder. Indigenous people can engage in critiques of authentication, which can include claims that, "I'm more "community" than you.' This notion of community as a combination of being on Country and in frequent direct contact with prominent cultural people, becomes a measure of power which is deployed as delegitimizing citizenship, and therefore as a means of knowing citizenship.

Hesitations to identify as Indigenous are exasperated through recent generations of Indigenous displacement and assimilation policies, which included the dismantling of Indigenous cultures' and reimagining and demanding that there is one Indigenous culture that is known to non-Indigenous people. As a consequence, Indigenous knowledge is rarely taught in mainstream education. Indigenous leaders, who may be influential, are rarely visible or unable to connect across dispersed communities. This means that there can be little, broadly available, nationspecific knowledge to identify with. Through continual dialogue among the team, non-Indigenous design practitioners and a key group of Wiradjuri 
people living in Melbourne, various ideas were explored that cohered as an event called Wiradjuri in Melbourne, as a moment for Wiradjuri people living 'off Country' to connect and be Wiradjuri together. Anecdotally, it was known that there were Wiradjuri people living in and around Melbourne, so the focus became ways to find Wiradjuri people through a mix of digital, audio and print media. This was the first known attempt to use broad reaching communication strategies to find and invite Wiradjuri people in Melbourne to gather as a cultural group, and in most cases, meet for the first time.

With this understanding, it was crucial that any communication assured Wiradjuri people that this was a safe and legitimate event that welcomed all levels of Wiradjuri experience and knowledge. Mark McMillan, leader of the Wiradjuri in Melbourne management group undertook radio interviews on RRR and $3 \mathrm{KnD}$. Both stations have a very specific audience; RRR is an 'alternative' youth station, while $3 \mathrm{KnD}$ is Melbourne's first Indigenous owned and operated radio station. In each case, the event was described in conversational terms, "just a chance to gather and "be" Wiradjuri, no one knows what this will be or look like, we've never done this before' so let's just give it a go...' (McMillan in Lee 2016). The tone is open and light-hearted and framed the event as a friendly, accessible, social occasion. The website, www.wiradjurioffcountry.com.au, acted as an information point to communicate the background, purpose, supporters and cultural protocols that led to this initiative. Wiradjuri nation has no agreed upon flag, logo or distinct colour palette, so instead, tone, humour and colloquial language was used to create an atmosphere of broad inclusion. Promotional bill (rock) posters were pasted on alleyways that physically placed Wiradjuri in the Melbourne streetscape. These posters included familial terms like 'cuz, bruz, sis' with a Melbournian 'hipster' note, 'Melbs', that features a semi-rhyme, reverse alliteration, which merges both Koori (a term that refers to Indigenous Australians of New South Wales and Victoria) lingo and localized catch phrasing. Expressions that already assume membership, such as 'join your mob', 'you're invited to gather' and 'be Wiradjuri' became a significant conceptual scaffold in all communication. 'Come and join your mob' is an affirmative invitation that places the viewer as Wiradjuri, in your mob. In this instance, the mob is citizenship.

Citizenship in this context is the act of being together, as a collective acknowledgement of Wiradjuriness. 'Being' is described as 'gathering with other Wiradjuri.' Wiradjuri citizenship and Wiradjuriness occur between Wiradjuri, through the collective knowing and acknowledgement of each other. Those who were willing to register were invited to tell their Wiradjuri story as a means of having a conversation with others. These acts of finding, registering and gathering become layered as transitional moments of tenuous, personal notions of citizenship and potentially an identity, undergoing discovery. These are all precarious, brave and empowering ways of strengthening Wiradjuri nation and identity as a collective.

Heterogeneity again features strongly here. It is glimpsed in the stories shared that trace multiple family-lines that are Indigenous and non-Indigenous, and for those with multiple Indigenous nationalities who foreground their Wiradjuriness in this gathering. There is also constant recognition of other sovereignties existing in places. The Wiradjuri gathering took place on Wurundjeri and Boonwurrung Country, the Kulin nation, which required an Elder from Wiradjuri Nation, Aunty Lorrine Tye, to travel from Wiradjuri County (Wagga Wagga) 
to make a formal request to the Wurundjeri Elder and Boonwurrung Elder for the event to be held in Melbourne. It is the Elders who are authorized to speak 'as Country' ${ }^{2}$ when they are pursuing diplomatic activities for cultural activities to be undertaken on another nations soil. It is important to note that permission was also sought and granted from Wiradjuri Elders for Wiradjuri people to exist culturally, 'off Country', in Melbourne. These cultural protocols are practised through diplomacy between Elders of Nations to respect mutual recognition of sovereignties. Such lawful act of mutual recognition of sovereigns was documented and communicated on the website, both as an assurance that cultural protocols were followed and as an outward demonstration of sovereignty. The sovereign recognition between Nation Elders is a practice that is born witness to, in a public forum, via the website.

\section{Consciousness of place and digital placemaking}

For many, sovereignty and Indigenous citizenship are situated and emplaced on Country. Country is a term used by Aboriginal people to refer to 'the land to which they belong and their place of Dreaming. Aboriginal language usage of the word country is much broader than standard English' (Australian Museum 2015). Country is much more than the land: it is also the place of jurisdiction and jurisprudence. There has always been governance existing of the land with the peoples that are connected to it. European conceptions of governance exist in tandem with the Indigenous nations that exist over the same 'territory' (McMillan and Rigney 2016).

Yet, what of those living 'off Country'? Here, we suggest that the digital and creative scaffolds brought consciousness to place as multiple, dynamic and socially constructed. Wiradjuri in Melbourne facebook group acted as a place of connection as found, registered members called out for more Wiradjuri mob to 'friend request' and add each other.

'Mandhang guwu Bala Mark \& Co! If any mob want to add me -feel free ^ _^ Guwayu!' Many posts included English and Wiradjuri language, which was often responded to in Wiradjuri. 'Such a deadly event!!! I'm feeling so empowered right now. Hope to see you all again soon!!! Guwayu xx'. Responses to 'Tag your mob', and 'Check in, off-country' became direct calls to action, ownership, recruitment and further connection. Familial connections and socially knowing other Wiradjuri became the basis of group invitations. As these connections are already known and trusted, this may explain why members would freely address the group as a collective and readily offer friendship requests. Addressing the 'group', rather than an anonymous singular 'you', indicates recognition of the importance of the collective and that, in this space, the digital gaze is from a group of Wiradjuri. Tags were shared from group members into their own facebook news feeds as a method of 'rippling out' membership. Recruitment moved into being the responsibility of the group. This ripple out effect built this place of belonging from within, an important starting point, when considering the need for authenticity through trusted sources in a cluttered digital environment.

This observation resonates with discussion on place-making in digital spaces, such as Soukup (2006), a media and technology scholar who describes how 'location' becomes more symbolic and is shaped by contexts, concerns and topics of conversation of those participating in the interaction. Place becomes a communication encounter (or 'performances') that is relationally produced by the participants. Here, place becomes 
similar to an 'event' that draws together people, things, time and space (Casey 1996). In contrast to space that is physically and literally defined, philosopher Casey $(1996,44)$ describes place as an 'arena of action' that is 'far from being static sites...[places are] continually changing in accordance with their own proper dynamism'.

Printed media on the street also invited a place-making communication encounter. In Wiradjuri, one poster called out for 'Babiin, Gunhi, Mudyi' with an English translation, 'Family, Friends, Uncles/Aunts' as secondary hierarchy in its legibility. The typographic use of language and its placement communicated an Indigenous or Wiradjuri event to the broader public. To the Wiradjuri audiences, it was a statement of Wiradjuri language in the Melbourne pedestrian landscape. This invited a moment of connection to culture and being culturally situated in Melbourne. Another poster used a stylized map of Wiradjuri and Wurundjeri Country (where Melbourne is located) that removed all colonial state borders, to recognize both as citizens. Wiradjuri and Wurundjeri are two names that are often mistaken due to phonetic similarity and a result of naïve ignorance of Indigenous nation knowledge by the general public. This brings consciousness to sharing place and continual place-making undertaken together among and between Indigenous and non-Indigenous people, beyond notions of the 'contact zone' that is often understood to be 'the space of colonial encounters...involving conditions of coercion, radical inequality and intractable conflict' (Pratt 1992, 6).

These affective, dynamic, temporal and co-constituted ways in which place-making can be facilitated by digital and creative scaffolds are also important to recognize as legitimate practices of being sovereign for Wiradjuri people, especially those living 'off Country'. We argue that this can enable a sovereign existence without knowing or being on Country. Such digital and creative scaffolds create, in Casey's $(1996,44)$ words, an 'arena of action' and an event that gathers together bodies, materials, affect and ideas for a shared connection of place for creating relationships. Place encompasses the physical, temporal, virtual spaces and it is the context in which meaning is made and lawful relations can constitute.

\section{From citizenship, sovereignty to Yindymarra}

In summary, we have problematized concepts of citizenship in digital media and communication contexts that only speak to identity-formation by starting with a premise of Indigenous sovereignty and citizenship in Australia that does not need to be asserted or constructed. Pursuing this argument, we have shared examples of various digital and creative scaffolds that were designed with Wiradjuri people as continuous 'infrastructuring' to express and practise Wiradjuri sovereignty. This exploration is enabling a political identity to form and creating multiple places to be Wiradjuri together. We have also discussed how designing digital and creative scaffolds can be considered as a meeting place of sovereigns to attend to a consciousness that non-Indigenous people are also practising their own sovereignty in relation to respecting Indigenous sovereignty/ies.

As digital and creative scaffolds are made, shaped and re-shaped by various forms of participation and encounter, transformation is also continually occurring to our lawful relations-among the research team and among the Wiradjuri people we engaged within physical and online spaces. For the non-Indigenous design and media team, this work is more than building a research relationship, but firstly as citizens, fundamentally about 
coexistence in Australia by sharing a place of dwelling and attending to their consciousness of being in lawful relationships with Indigenous nations. This inscribes the commitments that underpin their practice and their approach with an engaged consciousness as they pursue their work in the turbulent and uncertain contexts that accompany this journey. Such turbulence includes a vigilance and reflexivity of their own non-Indigenous worldviews that can be inscribed into the things they design while being open to interrogation by all. Having honest debates among the team and their Wiradjuri partners is another way of designing with, rather than designing for Wirajduri, where the italics nuance their concerns that suggest 'othering' and promote instrumental, dependent and service-provision relations. Instead, for the design and media team, designing with Wiradjuri is to be in accompaniment on a nation-building journey.

For the Wiradjuri co-authors, collaborating with the design and media team had further crystalized their way of acting, thinking and being Wiradjuri. The Wiradjuri ways of knowing and being is called Yindymarra, which means to show patience, respect, honour and to be courteous. Their Wiradjuri sovereignty, law relations and relationality allow them to know how to practise Yindymarra. Yindymarra is a beautiful Wiradjuri term and practice that can re-inscribe notions of citizenship, sovereignty and nations-words that unfortunately come laden with predetermined framing of power, boundary and governance that cannot sever a relationship with the colonial mapping of Australia. Faye McMillan, Wiradjuri research partner and co-author, says,

when we use language that is not our own [English], the term of being sovereign nation gets reflected in the "Western" legal construct ... but we are sovereign people. We create our own sovereignty and have done through our ancestors and continue today. It's getting people to strip the English away from it and be sovereign in Wiradjuri...Part of that is being reminded that... "stop thinking in English!" You are Wiradjuri, so therefore you think Wiradjuri and therefore you do Wiradjuri.... That's being a sovereign Wiradjuri person, citizen, woman.

Yindymarra resides in a different place, history and worldview that helps to shape new cartographies of understanding Indigenous relations to place and people in all its complexities. Such acts of naming and theorizing with, alongside designing with, are all part of our ongoing work to explore the limits of experiences and understanding of the Indigenous and non- Indigenous relationships. Arguably, such work is the material and the immaterial of infrastructuring; a fluid, emergent and contingent assemblage of sociomaterials that are articulated through INB so that sovereignty and citizenship in all its complex forms for Indigenous peoples can be understood, practised and shared.

\section{Notes}

1. Founded by Professors Stephen Cornell and Joseph P. Kalt at Harvard University in 1987, the Harvard Project on American Indian Economic Development (Harvard Project) is housed within the Malcolm Wiener Center for Social Policy at the John F. Kennedy School of Government, Harvard University. Through applied research and service, the Harvard Project aims to understand and foster the conditions under which sustained, self determined social and economic development is achieved among American Indian nations.

The Harvard Project's core activities include research, education and the administration of a tribal governance awards programme. In all of its activities, the Harvard Project collaborates with the Native Nations Institute for Leadership, Management and Policy at the University of Arizona. The Harvard Project is also formally affiliated with the Harvard University Native American Program, an interfaculty initiative at Harvard University. 
2. The Ngarrindjeri Regional Authority has had significant impacts on the evolution of such foundational concepts to Indigenous Nation Building in Australia. Of particular importance to this paper is the understanding of the KNY Agreements and the Ngarrindjeri Yannarumi - Speaking as Country. KNY is Kungun Ngarrindjeri Yunnan which translates to English as Listen to Ngarrindjeri talking.

\section{Acknowledgements}

The authors thank the Indigenous Nation Building collaborators that have influenced the work discussed in this paper, and acknowledge the immense body of scholarship by Professors Stephen Cornell, Daryle Rigney and Miriam Jorgensen; Associate Professor Steve Hemming; Dr Alison Vivian and Mr Damein Bell. Additionally, the authors are eternally indebted to the Gunditjmara Peoples, Wiradjuri and Ngarrindjeri Nation for sharing their knowledges. We would also like to thank the editors and reviewers of the paper, and in particular, Olivia Guntarik, whose feedback was invaluable. The work here also reflects the ongoing collaboration with design agencies, Bec Nally and PaperGiants (Reuben Stanton and Chris Marmo), communication design students and support from RMIT University.

\section{Disclosure statement}

No potential conflict of interest was reported by the author(s).

\section{Funding}

This work has been made possible through Australian Research Council grants led by the Jumbunna Indigenous House of Learning at the University of Technology, Sydney (UTS). The Melbourne School of Government has also funded research collaboration within Indigenous Nation Building framework in Australia.

\section{Notes on contributors}

Dr Yoko Akama is a participatory design researcher in the School of Media and Communication, RMIT University.

Ms Debra Evans is an Indigenous researcher, School of Indigenous Australian Studies, Charles Sturt University.

Dr Seth Keen is an interactive documentary producer and researcher in the School of Media and Communication, RMIT University.

Dr Faye McMillan, Wiradjuri woman, is the Member of the Trangie Land Council, and Director of Djurawang Program, Charles Sturt University.

Dr Mark McMillan, Wiradjuri man, is the Member of the Trangie Land Council, and Associate Professor University of Melbourne Law School. From March 2017 will be Deputy Pro ViceChancellor and Professor of Indigenous Education and Engagement at RMIT University.

Mr Peter West is a design researcher in communication strategies in the School of Media and Communication, RMIT University.

\section{References}


Akama, Yoko. 2015. "Being awake to Ma: Designing in between-ness as a way of becoming with." Co-Design: International Journal of CoCreation in Design and the Arts 11 (no. 3-4): 262-274.

Akama, Yoko, Seth Keen, and Peter West. 2016. "Speculative Design and Heterogeneity in Indigenous Nation Building." Proceedings of DIS '16 conference on designing interactive systems, 895-899.

Behrendt, Lisa. 2003. Achieving Social Justice: Indigenous Rights and Australia's Future. Annandale, NSW: The Federation Press.

Bidwell, Nicola, and Dianna Hardy. 2009. "Dilemmas in Situating Participation in Rural Ways of Saying." Proceedings of OZCHI '09: 145-152.

Bidwell, Nicola, Peta-Marie Standley, Tommy George, and Vicus Steffensen. 2008. "The Landscape's Apprentice: Lessons for Place- Centred Design from Grounding Documentary." Proceedings of DIS '08 conference on designing interactive systems, 88-98.

Björgvinsson, Erling, Pelle Ehn, and Per-Anders Hillgren. 2010. "Participatory Design and Democratizing Innovation." Proceedings of the participatory design conference (PDC '10), 41-50.

Black, Christine F. 2011. The Land is the Source of the Law: A Dialogic Encounter with Indigenous Jurisprudence. Abingdon: Routledge Cavendish.

Brereton, Margot, Paul Roe, Ronard Schroeter, and Anita Lee Hong. 2014. "Beyond Ethnography: Engagement and Reciprocity as Foundations for Design Research Out Here." Proceedings of $\mathrm{CHI}$ ' $14,1183-1186$.

Casey, Edward. 1996. "How to Get from Space to Place in a Fairly Short Stretch of Time." In Senses of Place, edited by Steven Feld and Keith H. Basso, 13-52. Santa Fe: School of American Research Press.

Chidgey, Red. 2014. "Developing Communities of Resistance? Maker Pedagogies, Do-ItYourself Feminism, and DIY Citizenship." In DIY Citizenship: Critical Making and Social Media, edited by Matt Ratto and Megan Boler, 101-114. Cambridge, MA: The MIT Press.

Cornell, Stephen. 2015. "Processes of Native Nationhood: The Indigenous Politics of SelfGovernment." The International Indigenous Policy Journal 6 (no. 4).

doi:10.18584/iipj.2015.6.4.4.

DiSalvo, Carl, Andrew Clement, and Volkmar Pipek. 2013. "Communities: Participatory Design for, with and by Communities." In Routledge International Handbook of Participatory Design, edited by Jesper Simonsen and Toni Robertson, 182-209. London: Routledge.

Dowell, Kristin L. 2013. Sovereign Screens: Aboriginal Media on the Canadian West Coast. Lincoln, NE: Nebraska Press. 
FitzSimons, Trish. 2009. "Braided Channels: A Genealogy of the Voice in Documentary." Studies in Documentary Film 3 (no. 2): 131-146.

Gooda, Mick. 2014. Social Justice and Native Title Report. Australian Human Rights Commission.

Graham, Laura R. 2016. "Toward Representational Sovereignty: Rewards and Challenges of Indigenous Media in the A'uwe-Xavante Communities of Eténhiritipa-Pimental Barbosa." Media and Communication 4 (no. 2): 13-32.

Hartley, John. 2009. Uses of Television. London: Routledge.

Heiss, Anita. 2012. Am I Black Enough for you? Biography. Random House.

Hemming, Steve, Daryle Rigney, and Shaun Berg. 2010. "Researching on Ngarrindjeri Ruwe/Ruwar: Methodologies for Positive Transformation." Australian Aboriginal Studies 2: 92-106.

Ingold, Tim. 1993. "The Temporality of the Landscape." World Archaeology 25: 152-174.

Lee, Kerri. 2016. "Breakfast with Kerri-Lee." In a Radio Broadcast Breakfast with Kerri-Lee, edited by Kerri Lee. Melbourne: 3KnD.

McMillan, Mark, and Sophie Rigney. 2016. "The Place of the First Peoples in the International Sphere: A Logical Starting Point for the Demand for Justice by Indigenous Peoples." Melbourne University Law Review 39 (no. 3): 981-1002.

Moreton-Robinson,Aileen. 2015. TheWhite Possessive: Property, Power and Indigenous Sovereignty. Minneapolis, MN: University of Minnesota Press.

Museum, Australian. 2015. http://australianmuseum.net.au/glossary-indigenous-australiaterms. Accessed 4 July 2016.

Pratt, Mary Louise. 1992. Imperial Eyes: Travel Writing and Transculturation. London: Routledge.

Purcell, Leah. 2002. Black Chicks Talking. Documentary. Film Australia.

Ratto, Matt, and Megan Boler. 2014. DIY Citizenship: Critical Making and Social Media. Cambridge, MA: The MIT Press.

Read, Peter. 1988. A Hundred Years War: The Wiradjuri People and the State. Canberra: Australian National University Press.

Sanders, Elizabeth B. 2002. "Scaffolds for Experiencing in the New Design Space." In Information Design, edited by Institute for Information Design Japan. Graphic-Sha 
Publishing.http://www.maketools.com/articlespapers/ScaffoldsforExperiencing_Sanders_03 .pdf.

Soukup, Charles. 2006. "Computer-Mediated Communication as a Virtual Third Place: Building Oldenburg's Great Good Places on the World Wide Web." New Media Society 8 (no. 421): 421-440.

Star, Susan Leigh, and Karen Ruhleder. 1996. "Steps Toward an Ecology of Infrastructure: Design and Access for Large Information Spaces." Information Systems Research 7 (no. 1): 111-134.

Tuhiwai-Smith, Linda. 2012. Decolonising Methodologies. New York: Zed Publications.

Vivian, Alison. 2014. "Aboriginal Self-Governance: Turning Practices into Rights in South Eastern Australia." Unpublished SJD diss., James E. Rogers College of Law, University of Arizona, Tucson, Arizona.

Vygotsky, Lev Semenovich. 1978. Mind in Society: The Development of Higher Psychological Processes. Cambridge, MA: Harvard University Press.

Willis, Anne-Marie. 2006. “Ontological Designing.” Design Philosophy Papers 4 (no. 2): 1-4.

Winschiers-Theophilus, Heike, Nicola Bidwell, and Edwin Blake. 2012. "Altering Participation Through Interactions and Reflections in Design." Co:Design: International Journal of CoCreation in Design and the Arts 8: 2-3.

Winschiers-Theophilus, Heike, Shilumbe Chivuno-Kuria, Gereon Koch Kapuire, Nicola J Bidwell, and Edwin Blake. 2010. "Being Participated-A Community Approach." Proceedings of PDC '10: 62-72. 